\title{
$\mathbf{M}_{\text {essage }}$
}

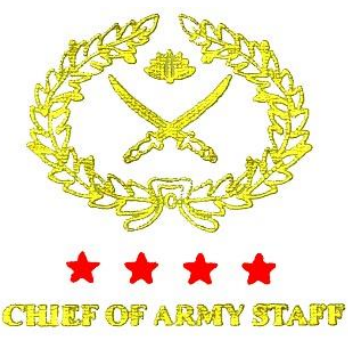

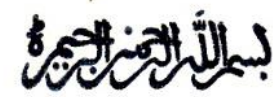

ARMY HEADQUARTERS

DHAKA CANTONMENT

Military Institute of Science and Technology (MIST) has taken a praiseworthy effort towards transforming its previous Journal - 'MIST Journal of Science and Technology' into an international journal founded on an Open Journal platform. The objective of the new Journal is to add value to the field of science and engineering. I appreciate timely initiative in upgrading MIST's Flagship Journal to 'Online Peer Reviewed Open Access.' The contents of 'MIST International Journal of Science and Technology (MIJST)' aptly reflect MIST's reputation and quality.

I am pleased that the launching of the December 2020 Issue of MIJST has been synchronized with the Victory Day of Bangladesh. Henceforth, it shall be published as the 'Victory Day Issue' to pay tribute to all the Martyrs and the Freedom Fighters of the Liberation War of Bangladesh. On this occasion, I also express my solemn respect and homage to the Father of the Nation, Bangabandhu Sheikh Mujibur Rahman on his centennial birth anniversary.

I wish MIJST's success in its noble mission of achieving the reputation of an international journal through meaningful research and dissemination of outputs in the field of cutting-edge Science and Technology!

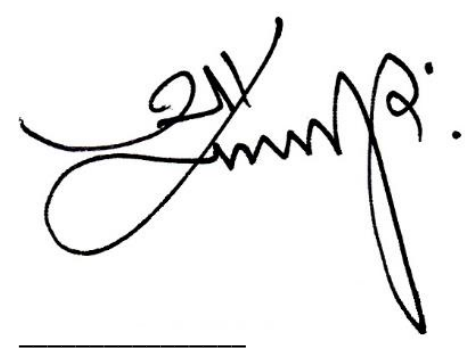

\section{AZIZ AHMED}

General

Chief of Army Staff

Bangladesh Army 